\title{
Relevant in Times of Turmoil: WHO and Public Health in Unstable Situations
}

\author{
Alessandro Loretti, MD; Xavier Leus, MD; Bart Van Holsteijn
}

\author{
Department of Emergency and \\ Humanitarian Action, World Health \\ Organization, Geneva, Switzerland \\ Correspondence: \\ Alessandro Loretti, MD \\ Department of Emergency and \\ Humanitarian Action \\ World Health Organisation \\ 20, Avenue Appia \\ CH-1211 Geneva 27 \\ Switzerland
}

Keywords: accountability; armed conflicts; assessments; challenges; chaos; commitment; complex emergencies; Department of Emergency and Humanitarian Action; disasters; donors; economics; emergencies; hazards; health; instability; instability spectrum; needs; Pan-American Health Organization (PAHO); planning; politics; resources; responsibilities; roles; systems; United Nations (UN); utopia; vulnerability; World Health

Organization (WHO)
Abbreviations:
$\mathrm{EHA}=$ Department of Emergency and Humanitarian Action (WHO)
IASC/WG = Inter-Agency Standing
Committee's Working Group
NGOs = non-governmental organiza- tions
OCHA = Office for Coordination of
Humanitarian Assistance
$\mathrm{PAHO}=$ the Pan-American Health
Organization
$\mathrm{PHC}=$ primary health care
UN $=$ United Nations
UNDAC = United Nations Disaster
Assessment and Coordination Team
$\mathrm{WHO}=$ World Health Organization

\begin{abstract}
For millions of people world-wide, surviving the pressure of extreme events is the predominant objective in daily existence. The distinction between natural and human-induced disasters is becoming more and more blurred. Some countries have known only armed conflict for the last 25 years, and their number is increasing. Recently, humanitarian sources reported 24 ongoing emergencies, each of them involving at least 300,000 people "requiring international assistance to avoid malnutrition or death". All together, including the countries still only at risk and those emerging from armed conflicts, 73 countries, i.e., almost 1.8 trillion people, were undergoing differing degrees of instability.

Instability must be envisioned as a spectrum extending between "Utopia" and "Chaos". As emergencies bring forward extreme challenges to human life, medical and public health ethics make it imperative for the World Health Organisation (WHO) to be involved. As such, WHO must enhance its presence and effectiveness in its capacity as a universally accepted advocate for public health. Furthermore, as crises become more enmeshed with the legitimacy of the State, and armed conflicts become more directed against countries' social capital, they impinge more on WHO's work, and WHO must reconcile its unique responsibility in the health sector, the humanitarian imperative and the mandate to assist its primary constituents.

Health can be viewed as a bridge to peace. The Organization specifically has recognised that disasters can and do affect the achievement of health and health system objectives. Within WHO, the Department of Emergency and Humanitarian Action (EHA) is the instrument for intervention in such situations. The scope of EHA is defined in terms of humanitarian action, emergency preparedness, national capacity building, and advocacy for humanitarian principles. The WHO's role is changing from ensuring a twoway flow of information on new scientific developments in public health in the ideal all-stable, all-equitable, well-resourced state, to dealing with sheer survival when the state is shattered or is part of the problem. The WHO poses itself the explicit goals to reduce avoidable loss of life, burden of disease and disability in emergencies and post-crisis transitions, and to ensure that the Humanitarian Health Assistance is in-line with international standards and local priorities and does not compromise future bealth development. A planning tree is presented.
\end{abstract}

The World Health Organization must improve its own performance. This requires three key pre-conditions: 1) presence; 2) surge capacity; and 3) institutional support, knowledge, and competencies. Thus, in order to be effective, WHO's presence and surge capacity in emergencies must integrate the institutional knowledge, the competencies, and the managerial set-up of the Organization.

Loretti A, Leus X, Van Holsteijn B: Relevant in times of turmoil: WHO and public health in unstable situations. Prebosp Disast Med 2001;16(4):184-191. 


\section{Challenges}

“...This compounding of extreme climatic events with rapid economic and institutional transition-collapse-presents a complex profile for future disasters. The poor, forced to live on marginal land in urban and coastal areas where jobs are concentrated will suffer most as the planet warms up and disaster strikes-96 percent of all deaths from natural disasters already bappen in developing countries [.....] The deadly combination of environmental change, economic inequity and political inaction will dominate the future of the bumanitarian scene."

IFRC

The first principle of Health is Life, and natural and manmade disasters threaten life and health. For millions of people world-wide, surviving the pressure of extreme events is the predominant objective in daily existence.

One sees countries undergo periodical disasters along apparently immutable patterns. Economic downturns combine with natural or technological hazards and trigger emergencies wherever or whenever the capacity is lacking to cope with them. The distinction between natural and human-induced disasters is becoming more and more blurred: the consensus is growing that there are no "natural" disasters. Natural or man-made hazards impact upon human vulnerabilities that are determined mostly by human causes. Thus, all emergencies can be said to have political causes; either by commission or by omission.

Complex emergencies are the most blatant instances. Some countries have known only armed conflict for the last 25 years, and their number is increasing. And, the $1990 \mathrm{~s}$ have seen the redefinition of the role of states, sometimes their collapse, and the explosion of wars in contexts of extreme vulnerability. Mid-1999, humanitarian sources reported 24 ongoing emergencies, each of them involving at least 300,000 people "requiring international assistance to avoid malnutrition or death". 1 All together, including the countries still only at risk and those emerging from armed conflicts, 73 countries, i.e., almost 1.8 trillion people, were undergoing differing degrees of instability. ${ }^{2}$

"Relief-Development Continuum" seems to have dropped out of the language of the international community. However, the issues underpinning that paradigm remain. Disasters and development are intertwined. Development is about change in human and environmental systems. In a context of rapidly increasing population and fast economic, technological, and social transitions, changes reach deeper and further. They become more radical and less predictable. They can engender crises that are more likely to catch people and societies unprepared, outstrip their coping capacities, and lead to disasters.

Change is inherent to human reality, and one can define as especially vulnerable those individuals, communities, and societies that have least means to influence and cope with the pace and shape of change. The greater the pace

and rate of change, the greater the instability and the risk.

\section{Defining Instability \\ When it comes to living in an environment of deteriorat- ing social service delivery systems which ultimately result in catastrophes, people's tolerance levels tend to increase to accept more episodes and interpret them as normal. The longer the situation continues the bigher the tolerance level and the less likely another incident or event will be inter- preted as dangerous enough to trigger a response.}

UNICEF

Instability* can be envisaged along a spectrum (Figure 1). At one end, "Utopia" represents an ideal, all-stable, allequitable, well-resourced society fully integrated and at ease in global geo-politics and economy. At the opposite end, in "Chaos", the society is shattered and societal factors lie at the root of the crisis, e.g., because the State itself applies and promotes violence against its own citizenry. The spectrum can be defined by the varying presence and interplay of natural and man-made factors of risk. Natural and/or man-made hazards are absent or effectively managed in "Utopia", while they are left unchecked until they "materialise as disasters" in "Chaos".

At the "Utopia" end of the spectrum, all surrounding systems are assumed to be functioning perfectly, and vulnerability essentially is individual and is determined by biological factors. At the "Chaos" end, vulnerability primarily is defined by socio-economic factors and largely collective. Conceptually, at least there is a strong rationale for different public health approaches.

\section{WHO and Emergencies}

All reality has implications for health, whether direct or indirect, and the World Health Organisation's (WHO's) responsibility for health does not cease in emergencies. On the contrary, as emergencies bring forward extreme challenges to human life, medical and public health ethics make it imperative for the Organisation to be involved. While working at how to optimise its comparative advantages, the WHO cannot selectively shed elements of its global responsibilities simply because they are complex or uncertain. Disasters, emergencies, and instability are public health concerns: dealing with them so as to reduce their impact in terms of illness and death is a fundamental responsibility of public-health practitioners. In these situations, WHO must enhance its presence and effectiveness in its capacity as a universally accepted advocate for public health.

The plight of people affected by any disaster is incompatible with WHO's definition of Health: Article 2 of WHO's constitution specifies the Organization's mandate to assist governments and special groups in emergency situations. Human survival and health are obvious cross-cutting objectives of all humanitarian endeavour.

Furthermore, as crises become more enmeshed with the

\footnotetext{
*The term "instability" is used with a degree of liberty. A system that is unstable is not necessarily bad. Likewise, "chaos" refers to a system that lacks evident structure and where prediction is difficult. Only in public parlance, it means "horrible, fast-changing, high-risk situation" and it is used here in this sense. For argument's sake, "chaos" and/or "extreme instability" are used to identify situations of high mortality risk, where there are more negative health outcomes, or the "likelihood of $300 \%$ plus increases in morbidity and mortality."
} 


\begin{tabular}{|c|c|c|}
\hline \multirow{2}{*}{$\begin{array}{l}\text { CATEGORIES } \\
\text { Geography }\end{array}$} & \multicolumn{2}{|c|}{ "UTOPIA" $\longleftrightarrow$ "CHAOS" } \\
\hline & $\begin{array}{l}\text { Easy access, good environmental } \\
\text { resource base }\end{array}$ & $\begin{array}{l}\text { Poor access, e.g. landlocked } \\
\text { Environmental degradation }\end{array}$ \\
\hline Climate & Absence of extreme phenomena & Drought, floods, storms \\
\hline Geology & No major geological hazard & $\begin{array}{l}\text { Earthquakes, landslides, volcanic } \\
\text { eruptions }\end{array}$ \\
\hline Biota & $\begin{array}{l}\text { Good balance between human systems } \\
\text { and potential pathogens }\end{array}$ & Epidemics, epizoonosis, pests \\
\hline Human & $\begin{array}{l}\text { Historically homogeneous; } \\
\text { "normal" demographic distribution }\end{array}$ & $\begin{array}{l}\text { Unchecked Growth Rate; } \\
\text { "Demographic entrapment"; } \\
\text { major distortions in sex/age } \\
\text { distribution; ethnic diversity and } \\
\text { strife }\end{array}$ \\
\hline $\begin{array}{l}\text { Economic } \\
\text { Infra-structure }\end{array}$ & $\begin{array}{l}\text { Sustainable availability of natural } \\
\text { resources } \\
\text { Stable and even distribution of } \\
\text { population }\end{array}$ & $\begin{array}{l}\text { Violent conflict for vital } \\
\text { resources; "infra-structural" } \\
\text { violence; forced human } \\
\text { displacement }\end{array}$ \\
\hline Regional Politics & $\begin{array}{l}\text { Good relations with neighbouring } \\
\text { countries }\end{array}$ & $\begin{array}{l}\text { Armed conflict with } \\
\text { bordering countries }\end{array}$ \\
\hline Economy & Sustainable and equitable growth & Economic crisis \\
\hline Society & Social cohesiveness and trust & Social disintegration; civil strife \\
\hline Culture & $\begin{array}{l}\text { Integrated, open to internal and } \\
\text { external factors of change }\end{array}$ & $\begin{array}{l}\text { Strife among/against minorities } \\
\text { Cultural and political isolation }\end{array}$ \\
\hline Governance & Good governance & Structural \& repressive violence \\
\hline $\begin{array}{l}\text { International } \\
\text { Relations }\end{array}$ & Good integration in global economy & $\begin{array}{l}\text { Marginalisation; sanctions; } \\
\text { "criminal" economy }\end{array}$ \\
\hline State Policies & "Rule of Law" & Structural \& repressive violence \\
\hline $\begin{array}{l}\text { Development } \\
\text { Policies }\end{array}$ & Equity, participation, safety & $\begin{array}{l}\text { Inequality; exclusion and violence, } \\
\text { technological disasters }\end{array}$ \\
\hline Service Policies & Equitable, effective, sustainable & Collapse of services \& lifelines \\
\hline \multirow{2}{*}{$\begin{array}{l}\text { Capacities for } \\
\text { Emergency } \\
\text { Management }\end{array}$} & In place, updated and sustained & $\begin{array}{l}\text { Absent: total dependence on } \\
\text { external assistance }\end{array}$ \\
\hline & \multicolumn{2}{|c|}{$0 \longleftarrow$ Instability Spectrum } \\
\hline
\end{tabular}

Figure 1-The Instability Spectrum. At the "Utopia" end of the spectrum, as all surrounding systems are assal and Disaster Medicineo 20 tioning, vulnerability is essentially individual and determined by biological factors. At the "chaos" end, vulnerability is primarily defined by socio-economic factors and largely collective. Conceptually at least, there is a strong rationale for different public health approaches.

crisis of legitimacy of the State, and armed conflicts become more directed against countries' social capital, they impinge more on WHO's work. As a United Nations (UN) Specialised Agency accountable to its member countries, WHO must reconcile its unique responsibility in the health sector, the humanitarian imperative, and the mandate to assist its primary constituents.

The World Health Organization is not new to disaster reduction, nor to humanitarian action. Already in the 1960 s, WHO was part of the UN operations in the newly independent Congo. ${ }^{3}$ On the strength of that experience and of that of Skopjie's earthquake, compounded by the need to meet the health needs of Palestine's Occupied Territories, $^{4}$ during 1969 and 1970, the Organization established a unit for Emergency Relief Operations in the office of the Director General. In the 1970s, the PanAmerican Health Organization's (PAHO's) Preparedness Program started translating the epidemiological method into a regional program for disaster reduction. Since, the Organization never has ceased to contribute to this area. 
Also in "complex emergencies", well before the term was coined and before the United Nations General Assembly (UNGA) Resolution 46/182,5 WHO had identified ways in which it could be effective in spite of the presence of armed conflict. In the 1980s, the Pan-American Health Organization (PAHO) was a key player in the preservation and restoration of the health sector in Central America, an experience that was to develop into concepts of health as a bridge to peace and of integrated primary health care (PHC) for refugee and host populations. ${ }^{6}$ From 1988-1992 in Mozambique ${ }^{7}$ and Afghanistan, WHO played a central role in the first attempts at humanitarian coordination by the United Nations (UN). The recurrent crises in the Northern and Southern Balkans promoted WHO's Regional Office for Europe to develop new approaches-the two most significant of which were the opening of sub-offices to get closer to the affected populations, and a declared "political" engagement to "Peace through Health. ${ }^{8}$ These experiences fed into various World Health Assembly resolutions and a growing, although uneven, presence of WHO in large humanitarian operations: from the Balkans to Africa's Great Lakes, from Indonesia, Iraq, and East Timor to West Africa and Colombia.

In Somalia, WHO has made a tangible difference in saving both lives and national capacities. In the recent earthquake in Gujarat, it was WHO that ensured the first de-centralized humanitarian coordination in the affected area. The WHO's experience of integrated assistance to displaced and host communities as a measure for post-crisis stabilization in Central America, Mozambique, Sri Lanka, and Bosnia-Herzegovina, ${ }^{9}$ still is far from being mainstreamed in the field practice of operational agencies facing "The Gap". The WHO's cross-border health programs in the Horn of Africa, between the USA and Mexico, and between Thai and Myanmar have scarce equivalents in the international scene, at least as far as inter-governmental cooperation is concerned. Major WHO-initiatives such as Roll Back Malaria, polio eradication, and Making Pregnancy Safer, include specific strategies for operating in complex emergencies. In the most troubled continent, Africa, it is WHO that had its member states adopt regional resolutions on peace as pre-condition for health, ${ }^{10}$ and on the need for preparedness against all emergencies, natural as well as man-made. ${ }^{11}$ The presence of the WHO in the Balkans and in Central Asia strives at combining health policy development with emergency preparedness and stabilization. In Indonesia, WHO plays an important role in risk monitoring, and is strongly committed to capacity building in and programme promotion to foster health as a bridge for peace. The Organization specifically has recognised that disasters, whether natural or resulting from human activities, ${ }^{12}$ can and do affect the achievement of health and health system objectives.

Within WHO, the Department of Emergency and Humanitarian Action (EHA) is the instrument for intervention in such situations. Interestingly, EHA's predecessor, the unit of Emergency Relief Operations, had been established by WHO to deal with the health aspects of the crisis in the Palestine Occupied Territories. Resolutions
46.6 and 48.2 of the World Health Assembly define the scope of EHA in terms of humanitarian action, emergency preparedness, national capacity building, and advocacy for humanitarian principles. Since 1997, a consultative process on WHO's role in emergencies and unstable settings has been going on around EHA. After a consultation on what the operational partners expected from the Organization in acute emergencies, ${ }^{13}$ the process accompanied the global debate in the public health and the humanitarian communities. This debate, which recognises public health as a cornerstone of humanitarian action, is shifting its focus from acute crisis management to mitigation, preparedness, and post-crisis transitions. The question of how to preserve and restore people's health in a vast range of situations of instability is increasingly coming into the limelight.

This process defined WHO's nine Core Corporate Commitments in emergencies (Table 1), that is the technical public health priorities that WHO must ensure regardless of the circumstances, because they are key to reducing avoidable mortality and morbidity. On the institutional plane, when developing the agenda for its 2nd Global Meeting in March 2001, WHO Country Representatives from all over the world requested that Disaster Preparedness and Response be included: these representatives reviewed the lessons learnt at the country level, and made important recommendations as to how WHO's responsibilities could be translated into practical activities within the context of instability and emergency. ${ }^{14}$

\section{Role of WHO in Unstable Situations}

Looking at the "Instability Spectrum" (Figure 2), WHO's role is changing from ensuring a two-way flow of information on new scientific developments in public health in the ideal, all-stable, all-equitable, well-resourced state, to dealing with sheer survival when the state is shattered or is part of the problem. National authorities are WHO's natural partners in "Utopia", while being able to work with/through the "International Relief Community" and a variety of other partners under the umbrella of the Inter-Agency Standing Committee's Working Group (IASC/WG) is the condition for effectiveness in "Chaos". In such settings, key priorities include coordination of action, contribution to field relief activities, and possibly, collection of evidence that can help to mobilize international political solutions. The greater the instability of the environment, the less health practitionersthe same as those from other disciplines - can do alone, and the wider is the vision and the capacity to understand and work in a multi-sectoral, complex frame of reality.

\section{Role and Responsibilities Are Clear: How to Satisfy Them?}

The World Health Organization poses itself the explicit goals "to reduce avoidable loss of life, burden of disease and disability in emergencies and post-crisis transitions," and "to ensure that the Humanitarian Health Assistance is in-line with international standards and local priorities and does not compromise future health development". The planning tree depicted in Figure 3, was produced by WHO staff during a workshop on Logical Framework Planning applied to conplex emergencies. ${ }^{15}$ Given the overall goal of 


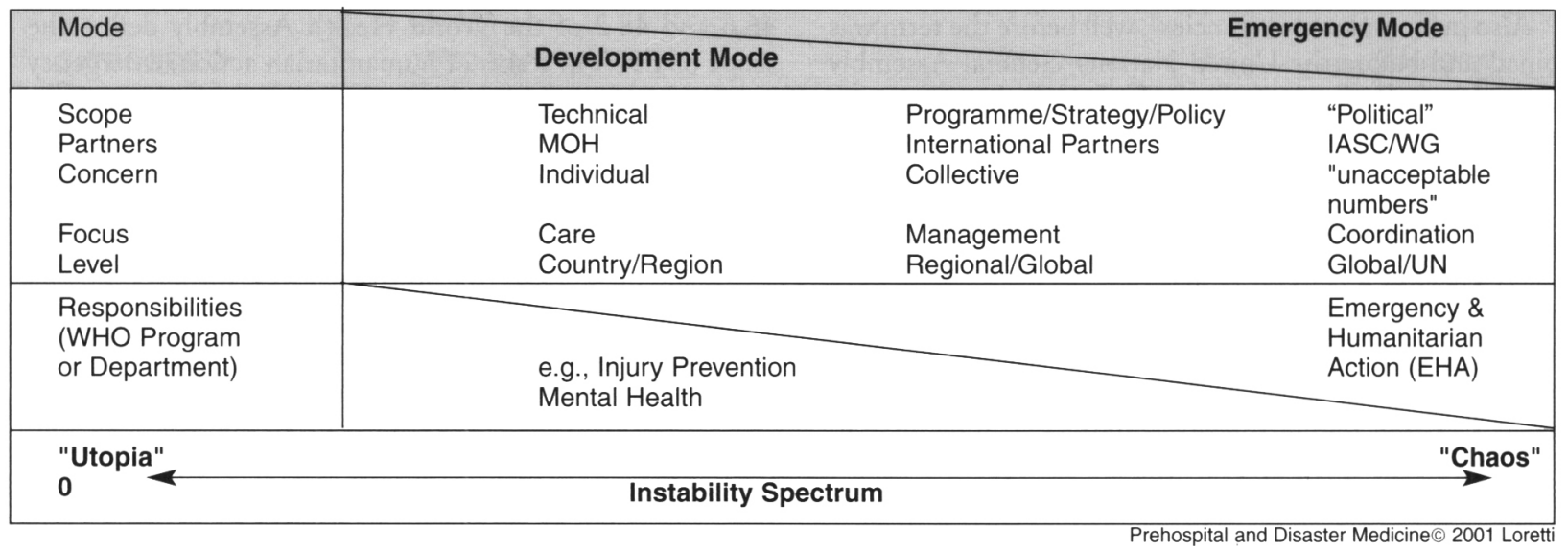

Figure 2-The Instability Spectrum and the roles of WHO

1. Identifying priority health and nutrition-related issues and ensuring that these are properly addressed in an integrated primary health care approach that preserves and strengthens local health system

2. Strengthening health and nutrition surveillance systems to enable monitoring of any changes, early warning of deterioration, and immediate life-saving action through outbreak response and technically sound nutrition interventions

3. Ensuring control of preventable ill health particularly communicable and vaccine-preventable diseases

4. Ensuring that risks related to the environment are recognised and properly managed

5. Ensuring good quality and access to basic preventive and curative care including essential drugs and vaccines for all, with special focus on the especially vulnerable - the elderly, the very young, pregnant women, the disabled and the chronically ill

6. Ensuring that Humanitarian Health Assistance is in line with international standards and local priorities and does not compromise future health development

7. Advocating and negotiating for secure humanitarian access, and neutrality and protection of health workers, services and structures as integral parts of public health promotion

8. Ensuring that the lessons learnt in a crisis are used to improve health sector preparedness for future crises and disaster reduction

9. Defining an integrated health policy for preparedness, emergency response and post-conflict, for a coherent health sector development resilient to emergencies

WHO/EHA, 2000

Table 1-WHO Core Commitments

Prehospital and Disaster Medicine@ 2001 Loretti

reducing avoidable mortality and morbidity (top of Figure), three specific objectives were identified as being critical for reducing avoidable mortality by reducing the risk of diarrhoeas, acute respiratory infection, malaria, measles, and epidemics, and for acute malnutrition. ${ }^{*}$

Proceeding further upstream (Figure 3), in order for these risks to be reduced, a number of outputs are needed: 1) safe water, shelter and environmental sanitation must be in place; 2) immunization; 3) distribution of vitamin A; 4) curative health care, and 5) appropriate general food rations. Always proceeding from the top of the figure to the bottom, these five sets of essential public health "products", in turn, must be sustained by precise activities: 1) epidemiological and nutritional surveillance; 2) strengthening local health resources and capacities; and 3) coordination of all operational partners, e.g., for water, sanitation, and food to be ensured. This provides a good summary of what is expected by health field workers during an emergency.

Requisite for these activities to take place, resources must reach as close to the needs as is possible. This, in turn, requires access, logistic capacities, and the resources themselves. Human and material resources and partially, logistics, depend essentially upon the availability of funds that must be mobilised. Access and to an extent, logistic options

*Inter Agency Standing Committee Working Group 


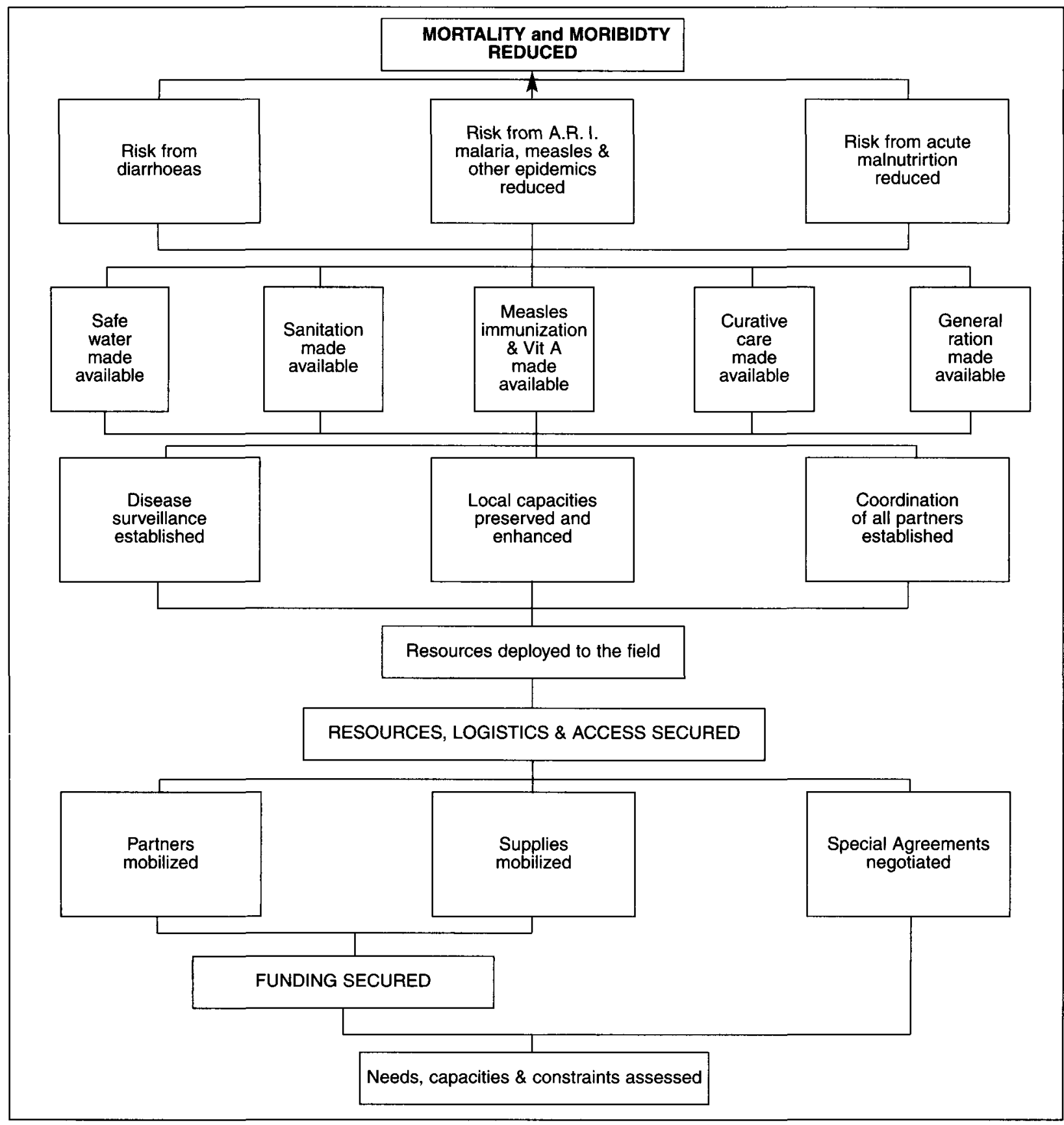

Prehospital and Disaster Medicine $\odot 2001$ Lorett

Figure 3-Planning tree for humanitarian response: Health goal, objectives, outputs, and activities (ARI = acute respiratory infections: Vit = vitamin)

require that special agreements and procedures be negotiated. This aspect is especially relevant in complex emergencies. However, in different ways, e.g., as standing operating procedures, pre-defined legal provisions, by-laws, and delegation of authority, it constitutes an important element of all emergency management systems.

The planning tree is "rooted" in the rapid assessments of the health needs that must be addressed, the capacities already in place, how much else is required so that the needs can be met, and the constraints that must be overcome, e.g., by negotiating humanitarian access and the assumptions that must be monitored in order for the project to be successful.

The planning tree reflects, with fair accuracy, the list of WHO's Core Commitments (Table 1). In practice, reducing avoidable mortality and morbidity in emergencies requires that the Organization has the operational capacity in the field and the credibility needed to ensure coordinated Public Health management for an immediate, optimal impact.

By deploying emergency public health experts or other specialists according to the needs, WHO can identify pri- 
ority health and nutrition needs, and ensure that these are addressed properly. As long as the rapid, health assessment is connected properly with the institutional memory of the WHO country office, the Organisation also can immediately prepare to bridge the gap between relief and recovery, by having life-saving priorities addressed in an integrated primary healthcare approach, thus preserving and strengthening the local health systems. Besides fulfilling the priority humanitarian responsibility, this also will satisfy WHO's mandate for contributing to collective publichealth learning and health sector accountability.

Whereas, it is true that WHO's main role is supporting the Ministry of Health through national officers, there is growing awareness that in emergencies, this not always is the only nor the best avenue for action. In many instances, supporting the Ministries of Health is essential, important, and effective. However, WHO increasingly is recognising the need to take a wider view of the health sector and healthrelevant partners, and often, to adopt different strategies, as well as to seek new, health-relevant partners. Adotping a precise, operational approach, WHO has learnt to decentralize its country activities during a crisis in order to ensure effective coordination of health relief where it is needed most, and to improve accountability and credibility. 15

This has been proven by experiences in countries in which war, conflict, and displacement are combined with a deteriorating health situation, epidemics, and a sudden increase of relief assistance by donors and non-governmental organizations (NGOs). These experiences formed the basis of the consensus that developed at the 2nd Global meeting of the WHO Country Representatives mentioned above. ${ }^{14}$

Looking at the health challenges posed by the current global context, the "role of WHO in emergencies" does not call for further debate. Neither do WHO's responsibilities: among member countries and partners, there is growing consensus that only WHO, as the UN Technical Agency for Health, is in the position to meet them unchallenged. Across WHO, high level political commitment is growing. In strategic terms, the next step is for WHO to achieve deeper institutional understanding, and to define the modus operandi that is best suited to fulfil this role and these responsibilities in practice.

\section{Moving Ahead: Making a Difference and Building a Reputation}

The World Health Organization must improve its own performance for the benefit of the populations affected by all disasters, as well as in order to fullfil its normative role with additional tools for public health management, and increase its accountability vis-à-vis member countries and international partners. This requires three key pre-conditions: 1) presence, 2) surge capacity; and 3) institutional support, knowledge, and competencies.

Today, through its Representatives, Country Liaison Officers, and Heads of Humanitarian Offices, WHO is present in 148 countries and territories worldwide. In addition, WHO sub-offices are becoming more numerous, and expand the Organization's operational capacity in special situations: from Somalia to Afghanistan, from the
Caucasus to Africa's Horn and Great Lakes regions, from Indonesia to Colombia, from Iraq to Angola. There is growing consensus across WHO that "wherever we feel that something is bound to happen", the Country Office must be strengthened. In coordination between Country, Region, and its Headquarters, dedicated officers are appointed as "EHA focal points" at the country level. The strategic objectives are to support national preparedness in the health sector, so that all member countries achieve readiness and self-reliance in the face of disasters, and to ensure that whenever an emergency takes place, a public health specialist is there to provide the first, life-saving actions and advice. Furthermore, following the example of PAHO, some strategically-sited WHO offices are being given sub-regional functions for emergency preparedness and response, e.g., to support and monitor cross-border humanitarian operations and capacity building. Similar experiences are underway also in the African Regional Office, (AFRO) and are being considered in the Western Pacific Regional Office, (WPRO). They are not yet institutionalised, but represent a positive trend that deserves support and replication.

Whatever WHO's presence at field level, an emergency-by definition-calls for extra-ordinary measures and resources. Therefore, WHO needs to have surge capacity to ensure that its public-health expertise is translated into concrete, life-saving actions. The strategic objective is to provide prompt additional, appropriate public health resources as needed-when and where needed. The experience of PAHO is that much can be done by mobilising regional and sub-regional solidarity and expertise. In fact, AFRO is consolidating regional, rapid response, health teams; such teams were quite successful during Mozambique's floods of 2000 . However, the reality is that, especially for complex emergencies, the capacity to deploy international, reputedly neutral experts through external assistance remains critical. Donor countries increasingly are demonstrating their capacities and goodwill in this area, e.g., for the crisis in Kosovo, the earthquakes in Turkey, and for the floods in Mozambique. Thus, EHA is exploring the feasibility for WHO to enter memoranda of understanding with major donors, by which human and material resources would be made available to the Organization for deployment "at 24 hours notice", under arrangements similar to those adopted by Office for Coordination of Humanitarian Assistance (OCHA) for the Office for Coordination of Humanitarian Assistance (UNDAC) and within WHO for the Emergency Revolving Fund. By appropriate induction briefing and technical monitoring, EHA would ensure that these additional resources are in line with the Organization's corporate strategy, technical views, and standard procedures. As a matter of fact, by guaranteeing a prompt and focused health response in natural and manmade disasters, WHO also would contribute greatly to improving the global humanitarian relief scene.

The tension between the humanitarian imperative and developmental work is considerable. But, public health professionals go back a long way in reconciling the apparent dualities of Health versus Disease, and Prevention versus Cure. However, WHO is more than a humanitarian health 
relief agency. It also is a UN Technical Agency, a "Learning Organization" that primarily is geared to, and genuinely reflects its Member States' priorities for sustainable public health. The Organization's work in emergencies cannot go divorced from this wider responsibility. Under the pressure of emergencies, it is too easy for external actors to ignore, if not trample over, national and local health systems, and bring immediate - and valuable - relief at the expenses of sustainable, long-term, health outcomes. Aspects of WHO's modus operandi may need to change in order to accommodate the "extraordinary measures" imposed by emergencies, but the Organization's views and concerns remain key for sound public-health practice in emergencies. It is thanks to its so often discussed "special relation" with the national health sector that WHO can ensure that the best public health practice in emergencies stems also from the experience and the needs of the beneficiaries, and not only from the capacities (or mandate) of external actors. Thus, in order to be effective, WHO's presence and surge capacity in emergencies must integrate the institutional knowledge, the competencies, and the managerial set-up of the Organization.

This means that the additional human and material resources deployed to ensure that WHO's presence and/or surge capacity predictably are in-line with the Organization's corporate strategy, technical views, and standard procedures. Meanwhile, WHO's country and regional offices need permanent access to technical expertise. Furthermore, their views represent the reality check of this expertise in emergencies, and they must be fed into the Organization's resource-allocation processes and institutional memory, as well as into global action for humanitarian assistance and development.

The bumanitarian imperative (the idea that buman suffering demands a response) fundamentally differs from the concept of development cooperation.... When alleviating poverty through development, the sustainability of the benefits of a given intervention is often the overriding indicator of success or failure, while the alleviation of human suffering is usually an indirect impact of the development process. In humanitarian action, the immediate imperative is concerned with saving lives and alleviating buman suffering.... Development is widely recognised as a politicised process whereas, historically, bumanitariasm was perceived to be independent or neutral... However, most bumanitarian agencies today acknowledge that bumanitarian aid is rarely non-political and neutral (Greenway, 1999)... Starting with the Hippocratic Oath (whereby "The health and life of the patient will be the first consideration"), justifications for provision of bealth services have always been intrinsically anchored in the humanitarian imperative. The Hippocratic Oath makes no reference to sustainability of poverty alleviation. Gro Harlem Brundtland bas stated that "Health is the cornerstone of humanitarian assistance, its ultimate objective, and the true yardstick against which one can evaluate needs for, and the overall performance of bumanitarian assistance.

P.Diskett and I.Christoplos for Sida, 2001

\section{References}

1. National Intelligence Council, August 1999.

2. World Health Organization: Planning Ahead for the Health Impact of Complex Emergencies. Geneva: World Health Organization, discussion draft, December 1999

3. Personal communications from Dr. C. de Ville de Goyet.

4. Personal communications from Dr. S.W.A. Gunn.

5. United Nations: Resolution A/RES/46/182 Strengthening of the Coordination Of Humanitarian Emergency Assistance of the United Nations. New York: United Nations, December 1991.

6. Guerra de Macedo C: Health for peace in Central America. Bulletin of the Pan American Health Organization 1986;20(1):62-66.

7. Pavignani E, Colombo A: Providing Health Services in Countries Disrupted by Civil Wars. A Comparative Analysis of Mozambique and Angola, 19752000. Geneva: World Health Organization / Emergency and Humanitarian Action, February 2001.

8. Hess G: The WHO/DFID Peace Through Health Programme. Geneva: World Health Organization, September 1998
9. Weiss Fagen P: Evaluation of Health and Develapment for Displaced Persons (HEDIP). Geneva: War-torn Societies Project, UNRISD, April 1995.

10. World Health Organization: Resolution $A F R / R C 46 / R$, Health and Peace Brazzaville. Africa Regional Office, September 1996.

11. World Health Organization: Resolution AFR/RC42/R11: Emergency Preparedness and Response, and Humanitarian Assistance in the African Region. Brazzaville: Africa Regional Office, September 1993.

12. World Health Organization: Resolution WHA 46.6: Emergency and Humanitarian Relief Operations. Geneva: World Health Organization, May 1993.

13. Toole MJ: Health Coordination in Emergencies: Options for the Role of WHO. Geneva, World Health Organization, concept paper, 1997.

14. World Health Organization: Report from the Second Global Meting of WHO Country Representatives and Liaison Officers. Geneva: World Health Organization, unpublished draft, March 2001.

15. World Health Organization: Internal WHO/EHA workshop: Planning by Logical Framework Approach. Addis Ababa: September 1997. 